\title{
Influence of noninvasive positive pressure ventilation on inspiratory muscle activity in obese subjects
}

\author{
W. Pankow, N. Hijjeh, F. Schüttler, T. Penzel, H.F. Becker, J.-H. Peter, P.v. Wichert
}

Influence of noninvasive positive pressure ventilation on inspiratory muscle activity in obese subjects. W. Pankow, N. Hijjeh, F. Schüttler, T. Penzel, H.F. Becker, J.-H. Peter, P.v. Wichert. OERS Journals Ltd 1997.

ABSTRACT: Noninvasive positive pressure ventilation (NPPV) can improve ventilation in obese subjects during the postoperative period after abdominal surgery. Compared to nasal continuous positive airway pressure (nCPAP), NPPV was superior in correcting blood gas abnormalities both during the night-time and during the daytime in a subgroup of patients with the obesity hypoventilation syndrome (OHS). However, as it is unknown, if and to what extent NPPV can unload the respiratory muscles in the face of the increased impedance of the respiratory system in obesity, this is what was investigated.

Eighteen obese subjects with a body mass index $\check{S} 40 \mathrm{~kg} \cdot \mathrm{m}^{-2}$ were investigated during the daytime, which included five healthy controls (simple obesity (SO)), seven patients with obstructive sleep apnoea (OSA) and six patients with the obesity hypoventilation syndrome (OHS). Assisted PPV was performed with bi-level positive airway pressure (BiPAP), applied via a face mask. Inspiratory positive airway pressure (IPAP) was set to 1.2 or $1.6 \mathrm{kPa}$ and expiratory positive airway pressure (EPAP) was set to $0.5 \mathrm{kPa}$. Inspiratory muscle activity was measured as diaphragmatic pressure time product (PTPdi).

Comparison of spontaneous breathing with BiPAP ventilation showed no significant difference in breathing pattern, although there was a tendency towards an increase in tidal volume (VT) in all three groups and a decrease in respiratory frequency $(f R)$ in patients with OSA and OHS. End-tidal carbon dioxide $\left(P E T, \mathrm{CO}_{2}\right)$ with BiPAP was unchanged in SO and OSA, but was decreased in OHS. In contrast, inspiratory muscle activity was reduced by at least $40 \%$ in each group. This was indicated by a decrease in PTPdi with BiPAP $1.2 / 0.5 \mathrm{kPa}$ from mean \pm SD $39 \pm 5$ to $20 \pm 9 \mathrm{kPa} \cdot \mathrm{s}$ $(p<0.05)$ in SO, from $42 \pm 7$ to $21 \pm 8 \mathrm{kPa} \cdot \mathrm{s}(\mathrm{p}<0.05)$ in OSA, and from $64 \pm 20$ to $38 \pm 17$ $\mathrm{kPa} \cdot \mathrm{s}(\mathrm{p}<0.05)$ in OHS. With BiPAP 1.6/0.5 $\mathrm{kPa}$, PTPdi was further reduced to $17 \pm 6$ $\mathrm{kPa} \cdot \mathrm{s}$ in SO, and to $17 \pm 6 \mathrm{kPa} \cdot \mathrm{s}$ in OSA, but not in OHS $(40 \pm 22 \mathrm{kPa} \cdot \mathrm{s})$.

We conclude that noninvasive assisted ventilation unloads the inspiratory muscles in patients with gross obesity.

Eur Respir J 1997; 10: 2847-2852.
Dept of Internal Medicine, Schlafmedizinisches Labor, Medizinische Poliklinik, Philipps-University, Marburg, Germany

Correspondence: W. Pankow

Krankenhaus Neukölln

Innere Medizin III

Rudower Straße 48

D-12351

Berlin

Germany.

Keywords: Inspiratory muscles noninvasive positive pressure ventilation obesity

obesity hypoventilation syndrome obstructive sleep apnoea

Received: April 171997

Accepted after revision September 301997

BiPAP is a registered trademark of Respironics Inc, Murrysville, Pennsylvania, USA.
In most patients with OSA hypercapnic and hypoxaemic episodes exclusively occur during sleep. In contrast, in a subgroup of grossly obese subjects hypoxaemia and hypercapnia persists throughout the daytime. This condition is commonly defined as obesity hypoventilation syndrome (OHS), if there is no additional intrinsic lung disease. Nasal continuous positive airway pressure (nCPAP) has been effectively used to prevent pharyngeal narrowing during sleep in patients with obstructive sleep apnoea (OSA) and even patients with OHS may respond to this treatment [1]. In some patients with OHS, however, nCPAP has proved to be ineffective in correcting hypercapnia and hypoxia both during sleep and wakefulness. In these cases, noninvasive positive pressure ventilation (NPPV) was found to be superior in terms of correction of nocturnal and daytime blood gases [2-4].

Recently, beneficial effects of NPPV have been shown in morbidly obese subjects undergoing abdominal surgery
[5]. Compared to a control group the prophylactic use of NPPV with bi-level positive airway pressure (BiPAP) postoperatively reduced pulmonary dysfunction after gastroplasty and accelerated reestablishment of preoperative lung function.

The mechanism, by which nocturnal NPPV improves the patients clinical condition in OHS is probably complex and might be related to a more physiological sleep architecture, correction of blood gas abnormalities and respiratory muscle unloading. The improvement of ventilatory function in the postoperative restrictive syndrome might also be multifactorial.

Unloading of the respiratory muscles with NPPV has been reported in chest wall restriction due to kyphoscoliosis [6], but no systematic investigation exists in patients with massive obesity. We hypothesized that unloading of the respiratory muscles might be achieved by NPPV in massive obesity and that this effect could contribute to 
the beneficial clinical effects of NPPV in obese patients who have an increased impedance of the respiratory system due to morbid obesity. We therefore studied diaphragmatic pressure time product (PTPdi) as an indicator of diaphragmatic energy expenditure during short-term application of assisted NPPV using the BiPAP ventilator.

\section{Methods}

\section{Subjects}

We studied eighteen subjects with marked obesity as defined by a body mass index (BMI) $\check{S} 40 \mathrm{~kg} \cdot \mathrm{m}^{-2}$. Fourteen subjects had been admitted to our institution because of suspected sleep apnoea. Six of these were hypercapnic (arterial carbon dioxide tension $\left(P \mathrm{a}, \mathrm{CO}_{2}\right)>6.0 \mathrm{kPa}(45$ $\mathrm{mmHg})$ ) and had peripheral oedema indicating right heart failure. All subjects reported loud and irregular snoring and all except one reported excessive daytime sleepiness (EDS). Four healthy obese volunteers without a history of loud snoring or EDS were also studied. No subject had complaints or clinical signs of chronic bronchitis or emphysema.

Before measurements started, all subjects underwent spirometric lung function testing and blood gas analysis. Predicted values of lung function tests were those of the European Coal and Steel Community (ECSC) [7]. Standard polysomnography was also performed in all subjects. The number of apnoeas and hypopnoeas divided by the sleep-time in hours was used to calculate an apnoea plus hypopnoea index (AHI). An AHI ð5 events. $\mathrm{h}^{-1}$ was considered normal [8]. In the four obese volunteers and in one otherwise healthy subject with suspected OSA, AHI was ð5, while in all other subjects AHI was well above this limit. Thus, there were three study groups: 1) five healthy subjects with obesity (simple obesity (SO)); 2) seven normocapnic obese patients with obstructive sleep apnoea (OSA); and 3) six hypercapnic obese patients with OSA and right heart failure (obesity hypoventilation syndrome (OHS)) [9]. Tables 1 and 2 provide anthropometric data

Table 1. - Anthropometric data

\begin{tabular}{|c|c|c|c|c|c|c|c|}
\hline & $\begin{array}{c}\text { Subjects } \\
\text { n }\end{array}$ & $\begin{array}{l}\text { Sex } \\
\mathrm{M} / \mathrm{F}\end{array}$ & $\begin{array}{l}\text { Age } \\
\text { yrs }\end{array}$ & $\begin{array}{l}\text { Weight } \\
\mathrm{kg}\end{array}$ & $\begin{array}{c}\mathrm{BMI} \\
\mathrm{kg} \cdot \mathrm{m}^{-2}\end{array}$ & $\begin{array}{l}\text { Smoking } \\
\text { S/ES/NS }\end{array}$ & $\begin{array}{l}\text { Pack- } \\
\text { years }\end{array}$ \\
\hline SO & 5 & $1 / 4$ & $42 \pm 20$ & $139 \pm 14$ & $43.5 \pm 4.5$ & $1 / 2 / 1$ & $4 \pm 8$ \\
\hline OSA & 7 & $3 / 4$ & $55 \pm 16$ & $128 \pm 25$ & $43.5 \pm$ & $1 / 5 / 1$ & $14 \pm 11$ \\
\hline OHS & 6 & $3 / 3$ & $52 \pm 10$ & $132 \pm 23$ & $46.0 \pm 6.2$ & $1 / 1 / 4$ & $10 \pm 10$ \\
\hline
\end{tabular}

Values are presented as mean \pm D . M: male; F: female; BMI: body mass index; S: smoking; ES: exsmoker; NS: nonsmoker; SO: simple obesity; OSA: obstructive sleep apnoea; OHS: obesity hypoventilation syndrome. and results of lung function and blood gas testing. All subjects gave their informed consent prior to the study. The study protocol was approved by the local Ethics Committee.

\section{Measurements}

Oesophageal $\left(P_{\text {oes}}\right)$ and gastric pressures $(P$ ga $)$ were measured using a catheter system with two piezoelectric pressure transducers located on the tip and $20 \mathrm{~cm}$ proximal to the tip of the catheter (GaelTec, Dunvegan, Isle of Skye, UK) [10]. A face mask (Respironics Inc., Murrysville, Pennsylvania, USA) was modified to accommodate this catheter system. The catheter was advanced until both tranducers were located intragastrically and then withdrawn until opposite phase directions appeared during respiratory efforts, indicating placement of the $P_{\text {oes }}$ transducer at the gastro-oesophageal junction. The catheter was then withdrawn another 8 to $13 \mathrm{~cm}$ until minimal cardiac artifact was present and optimal correlations within a $10 \%$ range of changes of mask pressure (ý $P$ mask) and oesophageal pressure (ýPoes) were recorded by means of the occlusion method [11]. The catheter was fixed to the nose by elastic tape to prevent dislocation while different body positions were assumed. Airflow $\left(V^{\prime}\right)$ was measured with a variable orifice pneumotachograph (Bicore, Irvine, CA, USA) attached to the face mask. A polyethylene catheter was connected to a side-port of the face mask to obtain mask pressure $(P$ mask). The pressure drop across the pneumotachograph and $P$ mask was measured with Microswitch 163PCOID36 and 143PC03D differential pressure tranducers (Honeywell Inc., Freeport, Illnois, USA). As the variable orifice sensor produces a nonlinear differential pressure signal to airflow, linearization of this signal must be performed. A microcomputer constructed to read the individual signal of the Bicore sensor (Bi-scope; Sing Medical, Stäfa, Switzerland) was used to perform this procedure. Dead space of the breathing assembly when applied to the subject was approximately $150 \mathrm{~mL}$. Combined resistance of the face mask and the flow-sensor when applied to the subject was measured as:

$$
R=\mathrm{K} 1+\mathrm{K} 2 V^{\prime}
$$

adapted from the Rohrer's equation

$$
P \text { res }=\mathrm{K} 1 V^{\prime}+\mathrm{K} 2 V^{\prime 2}
$$

where: $P$ res $=$ resistive pressure $(\mathrm{kPa}), V^{\prime}=$ airflow $\left(\mathrm{L} \cdot \mathrm{s}^{-1}\right)$, $\mathrm{K} 1$ = coefficient of linear resistance, $\mathrm{K} 2=$ coefficient of nonlinear resistance: $\mathrm{K} 1=0.158, \mathrm{~K} 2=0.016$. A mainstream infra-red capnograph (Novametrix Capnograph 7000; Novamterix Wallingford, Connecticut, USA) attached to the pneumotachograph allowed continuous determination of $P$ ET, $\mathrm{CO}_{2}$. Cardiac frequency (modified $\mathrm{V}_{2}$

Table 2. - Lung function data and baseline blood gases

\begin{tabular}{lllccccc}
\hline & $\begin{array}{c}\mathrm{FVC} \\
\% \text { pred }\end{array}$ & $\begin{array}{c}\mathrm{FEV} 1 \\
\% \text { pred }\end{array}$ & $\begin{array}{c}\mathrm{FEV} 1 / \mathrm{FVC} \\
\%\end{array}$ & $\begin{array}{c}\text { ERV } \\
\mathrm{L}\end{array}$ & $\begin{array}{c}\mathrm{Pa}_{\mathrm{a}, \mathrm{O}_{2}} \\
\mathrm{kPa}\end{array}$ & $\begin{array}{c}\mathrm{Pa}_{\mathrm{a}, \mathrm{CO}} \\
\mathrm{kPa}\end{array}$ & $\begin{array}{c}\text { AHI } \\
\text { events} \cdot \mathrm{h}^{-1}\end{array}$ \\
\hline SO & $95 \pm 11$ & $92 \pm 14$ & $78 \pm 6$ & $0.66 \pm 0.42$ & $10.8 \pm 1.3$ & $4.9 \pm 0.5$ \\
OSA & $87 \pm 15$ & $83 \pm 11$ & $85 \pm 8$ & $0.53 \pm 0.14$ & $8.6 \pm 0.9$ & $5.3 \pm 0.3$ & $78 \pm 38$ \\
OHS & $70 \pm 10$ & $64 \pm 8$ & $79 \pm 7$ & $0.36 \pm 0.24$ & $7.8 \pm 0.8$ & $6.5 \pm 0.4$ & $70 \pm 27$ \\
\hline
\end{tabular}

Values are presented as mean \pm S D FVC: forced vital capacity; FEV1: forced expiratory volume in one second; ERV: expiratory reserve volume; $P \mathrm{a}_{\mathrm{a}} \mathrm{O}_{2}$ : arterial oxygen tension; $\mathrm{Pa}_{\mathrm{a}, \mathrm{CO}_{2}}$ : arterial carbon dioxide tension; AHI: apnoea and hypopnoea index; $\%$ pred: percentage of predicted value. For further definitions refer to table $1.1 \mathrm{kPa}=7.52 \mathrm{mmHg}$. 
lead), blood pressure (Finapres; Ohmeda, Englewood, Colorado, USA) and arterial oxygen saturation $\left(\mathrm{Sa}_{\mathrm{a}} \mathrm{O}_{2}\right)(\mathrm{Biox}$ 3700 pulse oxymeter; Ohmeda, Boulder, USA) were also continuously recorded. The signals of flow, pressure, cardiac frequency and blood pressure were sampled at a rate of $100 \mathrm{~Hz}$ and the $\mathrm{Sa}_{\mathrm{a}} \mathrm{O}_{2}$ signal at a rate of $25 \mathrm{~Hz}$, using a computer data acquisition system with a built-in 12-bit analogue-to-digital converter (Topas; constructed by our group). The collected data were stored on optical disc for subsequent analysis. All variables were also recorded on a 16-channel strip chart recorder (Picker, München, Germany) at a paper speed of $10 \mathrm{~mm} \cdot \mathrm{s}^{-1}$. The flow signal was corrected for changes in gas temperature and gas composition. All pressure channels were calibrated using a water manometer.

\section{Study protocol and data analysis}

All investigations were performed in the morning at least $2 \mathrm{~h}$ after breakfast. The face mask was firmly attached. Performance of the occlusion test ensured that no airleaks were present. Subjects were studied supine with the upper part of the bed slightly elevated $\left(10^{\circ}\right)$ while breathing spontaneously for $12 \mathrm{~min}$ each. Then pressure support with BiPAP was initiated, starting with 1.2 $\mathrm{kPa}$ inspiratory positive airway pressure (IPAP) and then switching to $1.6 \mathrm{kPa}$ IPAP, while expiratory positive airway pressure (EPAP) was held constant at $0.5 \mathrm{kPa}$. Each level of inspiratory assist was applied for $12 \mathrm{~min}$. During the course of the experiments subjects were instructed to keep their eyes open in order to exclude the possibility that they were falling asleep. To minimize airleaks the mask was firmly tightened. During our experiments we tried to minimize air leaks by firmly tightening the mask and by subsequent repositioning if we noticed any leaks around the mask with our fingertips. The absence of leaks was continuously monitored from the flow signal tracing. Only periods without or with minimal end-expiratory flow shift from the zero line were analysed. BiPAP was applied by means of a bi-level continuous high flow $\left(120 \mathrm{~L} \cdot \mathrm{min}^{-1}\right)$ compressor-blower (BiPAP S/T- D; Respironics Inc.) set in the spontaneous BiPAP-mode. The unit was attached to the face mask distal to the capnograph with a special exhalation valve (Respironics whisper swivel valve, Respironics Inc.), which provides a fixed leak during use.

Measurements were obtained from at least 10 consecutive breaths during the last $2 \mathrm{~min}$ of each experimental condition. Volume $(V)$ was obtained by digital integration of the flow signal. Duration of inspiration $(t \mathrm{I})$ and expiration $(t \mathrm{E})$ was analysed from the flow tracing. Transdiaphragmatic pressure $(P \mathrm{di})$ was obtained electronically by subtraction of $P$ oes from $P$ ga. $P$ di at resting end-expiration (functional residual capacity (FRC)) was used as the zero reference point [12]. PTPdi was obtained by electronically integrating the area under the $P$ di-curve over $t \mathrm{I}$ [13] and calculated for $1 \mathrm{~min}$ (PTPdi) or for $1 \mathrm{~L}$ of ventilation.breath ${ }^{-1}(\mathrm{PTPdi} / V \mathrm{~T})$.

Comparisons between physiological data of unsupported breathing and NPPV were made using the Wilcoxon signed rank test. Error probability for significant results was determined as $\mathrm{p}<0.05$. All data are expressed as mean \pm SD.

\section{Results}

\section{Breathing pattern}

As shown in table 3, NPPV with BiPAP caused a tendency to increased $V \mathrm{~T}$ in all three groups. The $f \mathrm{R}$ decreased in the patients with OSA and OHS, but not in the SO subjects. This effect, however, was statistically significant only in the OHS group. In line with small changes in breathing pattern, $\mathrm{Sa}_{\mathrm{a}} \mathrm{O}_{2}$ was slightly higher and $P$ ET, $\mathrm{CO}_{2}$ slightly lower with each level of BiPAP compared to unsupported breathing, while no differences in cardiac frequency and blood pressure were detected (table 4).

Table 3. - Influence of noninvasive positive pressure ventilation on breathing pattern

\begin{tabular}{|c|c|c|c|}
\hline & Baseline & $\begin{array}{c}\text { BiPAP } \\
1.2 / 0.5 \mathrm{kPa}\end{array}$ & $\begin{array}{c}\text { BiPAP } \\
1.6 / 0.5 \mathrm{kPa}\end{array}$ \\
\hline \multicolumn{4}{|l|}{ SO } \\
\hline$V$ T $\mathrm{L}$ & $0.64 \pm 0.16$ & $0.79 \pm 0.28$ & $0.72 \pm 0.35$ \\
\hline$f_{\mathrm{R}}$ breaths $\cdot \min ^{-1}$ & $14.7 \pm 5.4$ & $14.0 \pm 3.4$ & $14.1 \pm 3.3$ \\
\hline$V^{\prime} \mathrm{E} \mathrm{L} \cdot \mathrm{min}^{-1}$ & $8.87 \pm 2.81$ & $11.12 \pm 5.26$ & $10.10 \pm 5.47$ \\
\hline$t \mathrm{I} / t$ tot $\%$ & $46 \pm 6$ & $42 \pm 8$ & $43 \pm 8$ \\
\hline \multicolumn{4}{|l|}{ OSA } \\
\hline$V \mathrm{~T} \quad \mathrm{~L}$ & $0.54 \pm 0.13$ & $0.57 \pm 0.14$ & $0.67 \pm 0.12$ \\
\hline$f_{\mathrm{R}}$ breaths $\cdot \mathrm{min}^{-1}$ & $19.4 \pm 4.1$ & $16.2 \pm 2.5$ & $16.4 \pm 3.1$ \\
\hline$V^{\prime} \mathrm{E} L \cdot \min ^{-1}$ & $10.14 \pm 1.83$ & $9.00 \pm 1.83$ & $10.55 \pm 1.23$ \\
\hline$t \mathrm{I} / / \mathrm{tot} \%$ & $43 \pm 5$ & $42 \pm 4$ & $42 \pm 6$ \\
\hline \multicolumn{4}{|l|}{ OHS } \\
\hline$V \mathrm{~T} \mathrm{~L}$ & $0.42 \pm 0.11$ & $0.57 \pm 0.21$ & $0.55 \pm 0.18$ \\
\hline$f \mathrm{R}$ breaths $\cdot \min ^{-1}$ & $20.8 \pm 3.3$ & $16.0 \pm 2.1^{*}$ & $17.5 \pm 4.0$ \\
\hline$V^{\prime} \mathrm{E} \cdot \mathrm{min}^{-1}$ & $8.35 \pm 1.86$ & $8.81 \pm 2.40$ & $9.10 \pm 2.28$ \\
\hline$t \mathrm{I} / t$ tot $\%$ & $40 \pm 6$ & $40 \pm 3$ & $42 \pm 5$ \\
\hline
\end{tabular}

Values are presented as mean $\pm S$ D. BiPAP: bi-level positive airway pressure. $V$ T: tidal volume; $f \mathrm{R}$ : respiratory frequency; $V$ 'E: minute ventilation; $t \mathrm{t}$ : inspiratory time; $t$ tot: total breathing cycle time; $t \mathrm{t} / \mathrm{ttot}$ duty cycle; *: $\mathrm{p}<0.05$ versus baseline. For further definitions refer to table 1 .

Table 4. - Influence of noninvasive positive pressure ventilation on blood gases, cardiac frequency $(f c)$ and blood pressure

\begin{tabular}{|c|c|c|c|}
\hline & Baseline & $\begin{array}{c}\text { BiPAP } \\
1.2 / 0.5 \mathrm{kPa} \\
\end{array}$ & $\begin{array}{c}\text { BiPAP } \\
1.6 / 0.5 \mathrm{kPa}\end{array}$ \\
\hline \multicolumn{4}{|l|}{ SO } \\
\hline $\mathrm{S}_{\mathrm{a}, \mathrm{O}_{2}} \%$ & $97 \pm 1$ & $99 \pm 1$ & $99 \pm 1$ \\
\hline$P$ ET, $\mathrm{CO}_{2} \mathrm{kPa}$ & $4.9 \pm 0.3$ & $4.4 \pm 0.8$ & $4.3 \pm 0.8$ \\
\hline$f_{\mathrm{C}}$ beats $\cdot \min ^{-1}$ & $73 \pm 4$ & $69 \pm 4$ & $69 \pm 2$ \\
\hline BPsys $\mathrm{kPa}$ & $19.8 \pm 3.1$ & $20.1 \pm 3.6$ & $18.5 \pm 3.5$ \\
\hline $\mathrm{BPdia} \mathrm{kPa}$ & $9.0 \pm 1.6$ & $9.7 \pm 1.3$ & $9.2 \pm 0.8$ \\
\hline \multicolumn{4}{|l|}{ OSA } \\
\hline${\mathrm{Sa}, \mathrm{O}_{2}}_{\mathrm{N}}$ & $94 \pm 2$ & $95 \pm 3$ & $96 \pm 2 *$ \\
\hline$P$ ET,, $\mathrm{CO}_{2} \mathrm{kPa}$ & $4.9 \pm 0.5$ & $4.9 \pm 0.7$ & $4.7 \pm 0.4$ \\
\hline$f_{\mathrm{C}}$ beats $\cdot \mathrm{min}^{-1}$ & $84 \pm 12$ & $81 \pm 10$ & $79 \pm 7$ \\
\hline BPsys $\mathrm{kPa}$ & $19.3 \pm 4.3$ & $18.8 \pm 2.3$ & $20.3 \pm 2.9$ \\
\hline BPdia $\mathrm{kPa}$ & $10.1 \pm 3.2$ & $9.6 \pm 1.6$ & $10.6 \pm 2.3$ \\
\hline \multicolumn{4}{|l|}{ OHS } \\
\hline$S_{\mathrm{a}, \mathrm{O}_{2}} \%$ & $86 \pm 4$ & $89 \pm 2$ & $90 \pm 2 *$ \\
\hline$P{\mathrm{ET}, \mathrm{CO}_{2}}_{2} \mathrm{kPa}$ & $6.0 \pm 0.4$ & $5.5 \pm 0.5^{*}$ & $5.5 \pm 0.5^{*}$ \\
\hline$f_{\mathrm{C}}$ beats $\cdot \mathrm{min}^{-1}$ & $97 \pm 28$ & $96 \pm 29$ & $107 \pm 24$ \\
\hline BPsys $\mathrm{kPa}$ & $18.2 \pm 3.2$ & $17.4 \pm 3.6$ & $15.7 \pm 1.5$ \\
\hline BPdia $\mathrm{kPa}$ & $10.0 \pm 1.5$ & $9.7 \pm 1.3$ & $9.8 \pm 1.3$ \\
\hline
\end{tabular}

Values are presented as mean $\pm S D$. BiPAP: bi-level positive airways pressure; $\mathrm{Sa}_{\mathrm{a}} \mathrm{O}_{2}$ : arterial oxygen saturation; $P \mathrm{ET}, \mathrm{CO}_{2}$ : endtidal carbon dioxide pressure; BPsys: systolic blood pressure; BPdia: diastolic blood pressure. *: $\mathrm{p}<0.05$ versus baseline. For further definitions refer to table $1.1 \mathrm{kPa}=7.52 \mathrm{mmHg}$. 

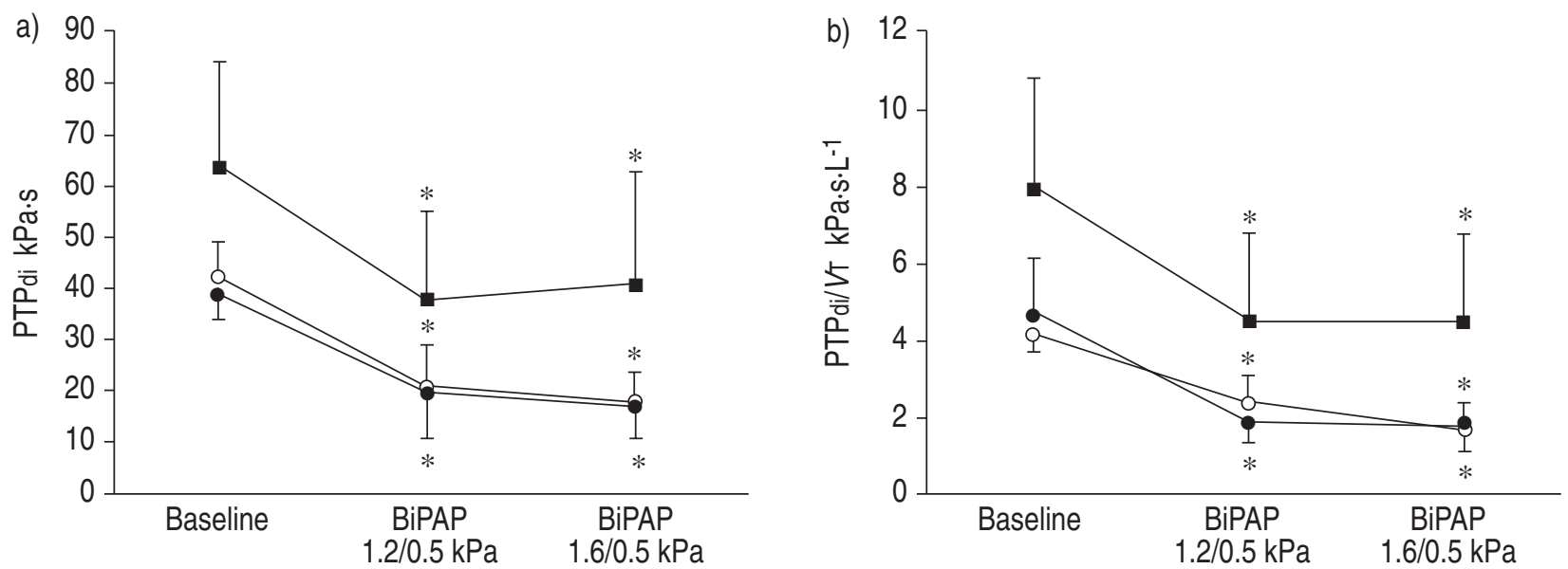

Fig. 1. - Pressure-time products of the diaphragm (PTPdi): a) calculated for $1 \mathrm{~min}$ (PTPdi); b) calculated on a per breath basis for $1 \mathrm{~L}$ (PTPdi/tidal volume $(V \mathrm{~T})$ ). $\mathbf{\square}$ : obesity hypoventilation syndrome; $\bullet$ : obstructive sleep apnoea; $\bigcirc$ : simple obesity. BiPAP: bi-level positive airway pressure. *: p<0.05 compared to baseline.

a)

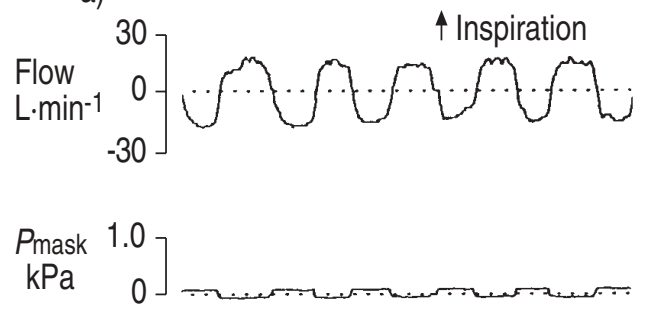

Poes

$\mathrm{kPa}$
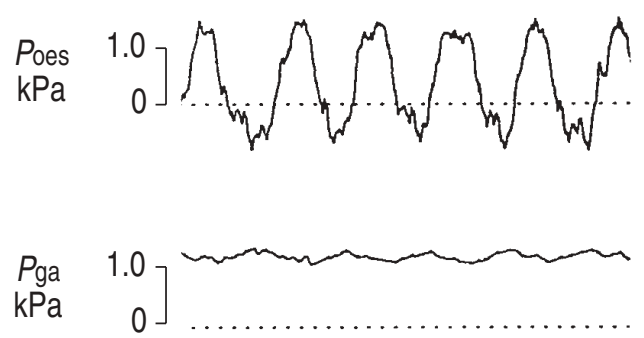

$P \mathrm{di}$
$\mathrm{kPa}$

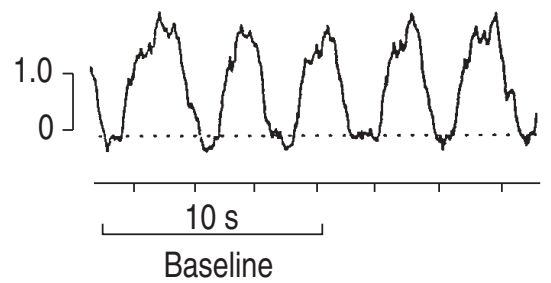

b)
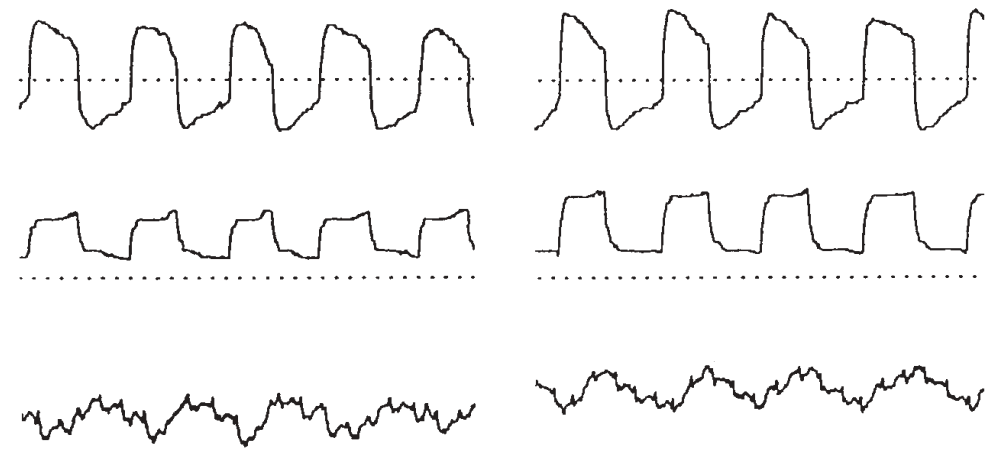

c)

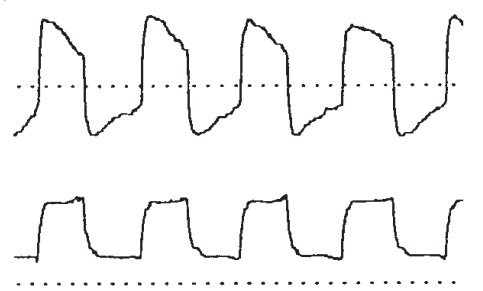

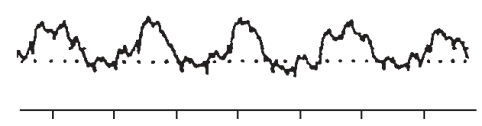

BiPAP 1.2/0.5 kPa
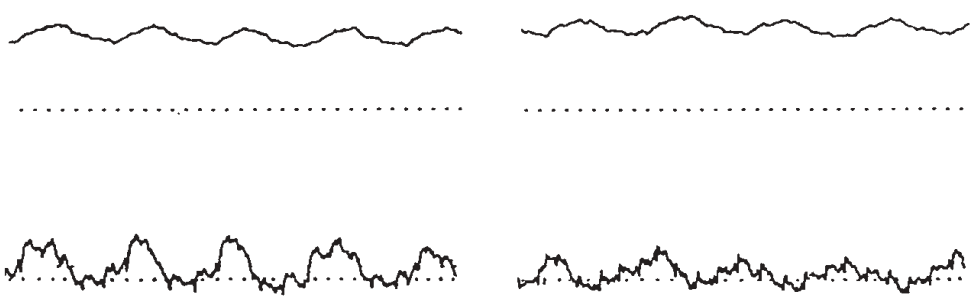

BiPAP 1.6/0.5 kPa

Fig. 2. - Tracings obtained from a representative subject during: a) unsupported breathing; b) noninvasive positive pressure ventilation (NPPV) with bi-level positive airways pressure (BiPAP) $1.2 / 0.5 \mathrm{kPa}$; and c) NPPV with BiPAP 1.6/0.5 kPa. Flow: airflow; $P$ mask: mask pressure; $P$ oes: oesophageal pressure; $P$ ga: gastric pressure; $P_{\mathrm{di}}$ : transdiaphragmatic pressure. Note, that with increasing levels of pressure support, tidal swings of $P_{\mathrm{oes}}$ and $P_{\mathrm{di}}$ are reduced. This indicates transformation of breathing work from the patient to the ventilator. Note also, that end-expiratory $P_{\text {oes }}$ with BiPAP is slightly increased. This might indicate increased functional residual capacity, induced by the positive end-expiratory pressure. See text for further details.

As shown in table 3, NPPV with BiPAP caused a tendency to increased $V \mathrm{~T}$ in all three groups. The $f \mathrm{R}$ decreased in the patients with OSA and OHS, but not in the SO subjects. This effect, however, was statistically significant only in the OHS group. In line with small changes in breathing pattern, $S \mathrm{a}, \mathrm{O}_{2}$ was slightly higher and $P \mathrm{ET}, \mathrm{CO}_{2}$ slightly lower with each level of BiPAP compared to unsupported breathing, while no differences in cardiac frequency and blood pressure were detected (table 4).

\section{Inspiratory muscle activity}

During baseline breathing PTPdi and PTPdi/VT were similar in SO and OSA, but were significantly $(\mathrm{p}<0.05)$ higher in OHS (fig. 1a and b).

Tracings during unsupported breathing and during assisted ventilation in one representative subject in figure 2 show that inspiratory muscle activity with BiPAP was reduced. This is indicated by the reduction in pressure 
swings of $P$ oes and $P$ di. Compared to unsupported breathing PTPdi with BiPAP $1.2 / 0.5 \mathrm{kPa}$ was reduced from $39 \pm 5$ to $20 \pm 9 \mathrm{kPa} \cdot \mathrm{s}(\mathrm{p}<0.05)$ in $\mathrm{SO}$, from $42 \pm 7$ to $21 \pm 8 \mathrm{kPa} \cdot \mathrm{s}$ $(\mathrm{p}<0.05)$ in OSA, and from $64 \pm 20$ to $38 \pm 17(\mathrm{p}<0.05)$ in OHS. With BiPAP 1.6/0.5 kPa PTPdi was further reduced to $17 \pm 6 \mathrm{kPa} \cdot \mathrm{s}$ in $\mathrm{SO}$, to $17 \pm 6 \mathrm{kPa} \cdot \mathrm{s}$ in OSA, but not in OHS (40 $\pm 22 \mathrm{kPa} \cdot \mathrm{s})$ (fig. 1a). When PTPdi was calculated on a per breath basis for $1 \mathrm{~L}$ of ventilation, comparable results were obtained (fig. 1b).

\section{Discussion}

This study shows that NPPV can unload the inspiratory muscles of grossly obese subjects. We used inspiratory pressure assist limited to $1.6 \mathrm{kPa}$ because otherwise airleaks would have restricted the exact measurement of airflow. Higher pressures might have further reduced respiratory muscle activity, but in our experience pressures of more than $2.0 \mathrm{kPa}$ are rarely tolerated and cannot be applied with the ventilator used in this study. In a previous investigation total muscle unloading was achieved with a pressure support level of $3.0 \mathrm{kPa}$ in intubated normalweight patients with respiratory failure [14]. Therefore, total respiratory muscle rest in obesity can certainly not be achieved with noninvasive ventilation, since only limited positive pressures can be applied via face masks to the patient. The $46 \%$ reduction in diaphragmatic activity, nevertheless, is more than we had expected in the face of gross obesity in the patients of this investigation. In the SO and OSA group we observed a further reduction in PTPdi with BiPAP 1.6/0.5 kPa compared with BiPAP 1.2/ $0.5 \mathrm{kPa}$, which, however, was not statistically significant. In the OHS group there was no further reduction in PTPdi with the higher pressure. However, due to the relatively small number of patients and the small difference between the two levels of BiPAP, it cannot be assumed that there definitely is no further decrease in PTPdi with higher levels of BiPAP.

With BiPAP we used an assisted mode of NPPV, that combines CPAP and pressure support by setting different levels of EPAP and IPAP. Since with pressure support the patient controls inspiratory flow, $f \mathrm{R}$ and expiratory time to some degree, the effect of mechanical ventilation is not only dependent on the pressure support level, but also on the patient-ventilator interaction [15]. Depending on the ventilatory drive, the patient can use the machine work either to increase ventilation or reduce his own work of breathing at a given level of ventilation or combine these two effects. Because breathing pattern and $P$ ET, $\mathrm{CO}_{2}$ changed only slightly with BiPAP, it follows that the respiratory controller gave a higher priority to muscle unloading. We observed, however, a tendency towards improved ventilation. This could indicate, that ventilation is normalized after a longer period of NPPV.

Breathing during our experiments was certainly stimulated by rebreathing carbon dioxide from the high dead space of the face mask. However, as this factor was kept constant throughout the entire test, dead space should not have influenced our results.

In obesity the increased abdominal load shifts the diaphragm in the upward direction, thereby decreasing expiratory reserve volume and FRC [16]. As a result, obese subjects breathe at low lung volumes along the very flat portion of the already flattened pressure-volume curve.
With the low level of EPAP $(0.5 \mathrm{kPa})$, we chose a ventilator setting, which in an earlier study [4] effectively prevented upper airway obstruction during sleep in patients with OHS. In contrast to this study, our experiments were performed in awake subjects. Here, CPAP might have increased FRC. This is indicated by the increased endexpiratory $P_{\text {oes }}$ (see fig. 2). With increased FRC tidal breathing is performed along the steeper portion of the compliance curve, so work of breathing is decreased. Thus, in addition to pressure support, CPAP could have contributed to the reduced diaphragmatic activity in our study.

Patients with OHS had a higher BMI than the OSA and SO subjects. This might have led to lower expiratory reserve volume and higher PTPdi in these patients. There is evidence however, that the increased PTPdi is mainly related to intrinsic factors associated with OHS. Lung and chest wall compliance in OHS is lower and work of breathing is increased compared with SO [17, 18]. This difference is unexplained by differences of weight in the two groups of subjects [17]. In addition, OHS is characterized by persistent inadequate ventilatory compensation for these extra loads $[9,19]$, a result of which is chronic hypercapnia during the daytime. It is speculated that in OHS the combination of obesity-related alterations of chest wall and lung mechanics and increased inspiratory load due to functional upper airway obstruction during sleep may induce respiratory muscle fatigue [20]. This concept is supported by the observation that in some patients with OHS nocturnal splinting of the upper airway with nCPAP results in rapid normalization of daytime blood gases [1].

In some patients, however, nCPAP is not sufficient to prevent nocturnal hypoxaemia [21] and intermittent or permanent NPPV is required. One study [3] and several reports of small numbers of patients $[4,22]$ or case reports $[23,24]$ have shown that nocturnal application of NPPV can effectively improve blood gases in OHS. One of several mechanisms also proposed to normalize ventilation during the daytime is respiratory muscle rest [3]. Other mechanisms may add to these beneficial effects. These include improvement of central respiratory drive, ventilation of atelectatic lung areas with reduced ventilation-perfusion mismatch and improvement of sleep architecture.

A problem of this study might be that measurements were performed during the daytime, while patients with OHS are generally ventilated at night. Our hypothesis was that NPPV can unload the respiratory muscles despite the increased mechanical impedance of the respiratory system. In obesity, work of breathing is increased as a result of decreased lung and chest wall compliance [18, 25]. This factor is largely independent of the state of vigilance and can therefore be studied during the daytime. Thus, although we have not done our measurements at night, we might hypothesize that our findings are also valid during sleep. Still, this assumption needs confirmation. Upper airway narrowing during sleep will cause additional muscle loading in OSA and OHS and sleep itself alters respiratory drive, which is important in respect to patient-ventilator interaction in modes of partial ventilatory support. Thus, although we think that muscle unloading with BiPAP will be present during sleep, it cannot be assumed that the settings of the ventilator used in the present study will be equally effective in ventilating patients during sleep. 
The rationale to investigate different groups of subjects with obesity was to show that respiratory muscle unloading can be effectively performed in obesity irrespective of additional problems like OSA or OHS. Most subjects with $\mathrm{SO}$ as well as normocapnic OSA (treated with nCPAP) will not experience problems associated with obesity-related respiratory muscle load. It has been demonstrated, however, that grossly obese patients have an increased risk of respiratory complications in the perioperative period [26-28], and that noninvasive mechanical ventilation can improve the ventilatory function [5]. We have now shown that NPPV can provide partial respiratory muscle rest. We suggest that this mechanism might have contributed to the beneficial clinical effects of NPPV demonstrated in earlier investigations.

In summary, the data of this study show for the first time that the diaphragm in extreme obesity and in the obesity hypoventilation syndrome is unloaded, though not completely rested with noninvasive positive pressure ventilation. Improvement of the clinical condition shown in earlier investigations might, in part, be due to this mechanism. Our results also suggest that in acute respiratory failure as a complication of obesity hypoventilation syndrome, or during the postoperative period, noninvasive ventilation might be used as an alternative to invasive ventilation.

Acknowledgement: The authors would like to thank M. Aarts for reviewing the English of the manuscript.

\section{References}

1. Shivaram U, Cash ME, Beal A. Nasal continuous positive airway pressure in decompensated hypercapnic respiratory failure as a complication of sleep apnea. Chest 1993; 104: 770-774.

2. Bott J, Baudouin SV, Moxham J. Nasal intermittent positive pressure ventilation in the treatment of respiratory failure in obstructive sleep apnoea. Thorax 1991; 46: 457458.

3. Piper AJ, Sullivan CE. Effects of short-term NIPPV in the treatment of patients with severe obstructive sleep apnea and hypercapnia. Chest 1994;105: 434-440.

4. Waldhorn RE. Nocturnal nasal intermittent positive pressure ventilation with bi-level positive airway pressure (BiPAP) in respiratory failure. Chest 1992; 101: 516-521.

5. Joris JL, Sottiaux TM, Chiche JD, Desaive CJ, Lamy ML. Effect of bi-level positive airway pressure (BiPAP) nasal ventilation on the postoperative pulmonary restrictive syndrome in obese patients undergoing gastroplasty. Chest 1997; 111: 665-670.

6. Carrey Z, Gottfried SB, Levy RD. Ventilatory muscle support in respiratory failure with nasal positive pressure ventilation. Chest 1990; 97: 150-158.

7. European Coal and Steel Community. Standardiziation of lung function test. Bull Eur Physiopathol Respir 1983; 19: 1-95.

8. Young T, Palta M, Dempsey J, Skatrud J, Weber S, Badr $\mathrm{S}$. The occurence of sleep disordered breathing among middle-aged adults. N Engl J Med 1993; 328: 1230-1235.

9. Lopata M, Önal E. Mass loading, sleep apnea, and the pathogenesis of obesity hypoventilation. Am Rev Respir Dis 1982; 126: 640-645.

10. Panizza J, Finucane KE. Comparison of balloon and transducer catheters for estimating lung elasticity. $J$ Appl Physiol 1992; 72: 231-235.

11. Baydur A, Behrakis KP, Zin WA, Jaeger M, Milic-Emili J. A simple method for assessing the validity of esophageal balloon technique. Am Rev Respir Dis 1982; 126: 788-791.

12. Mier A, Brophy C, Moxham J, Green M. Influence of lung volume and rib cage configuration on transdiaphragmatic pressure during phrenic nerve stimulation in man. Respir Physiol 1990; 80: 193-202.

13. Annat GJ, Viale JP, Dereymez CP, Bouffard YM, Delafosse BX, Motin JP. Oxygen cost of breathing and diaphragmatic pressure-time index. Chest 1990; 98: 411-414.

14. Banner MJ, Kirby RR, Gabrielli A, Blanch PB, Layon AJ. Partially and totally unloading respiratory muscles based on real-time measurements of work of breathing. Chest 1994; 106: 1835-1842.

15. Younes M. Patient-ventilator interaction with pressureassisted modalities of ventilatory support. Sem Respir Med 1993; 14: 299-322.

16. Ray CS, Sue DY, Bray G, Hansen JE, Wassermann K. Effects of obesity on respiratory function. Am Rev Respir Dis 1983; 128: 501-506.

17. Sharp JT, Henry JP, Sweany SK, Meadows WR, Pietras RJ. The total work of breathing in normal and obese men. J Clin Invest 1964; 43: 728-739.

18. Naimark A, Cherniak RM. Compliance of the respiratory system and its components in health and obesity. J Appl Physiol 1960; 15: 377-382

19. Rochester DF, Enson Y. Current concepts in the pathogenesis of the obesity-hypoventilation syndrome. Am J Med 1974; 57: 402-420.

20. Martin TJ, Sanders MJ. Chronic alveolar hypoventilation: a review for the clinician. Sleep 1995; 18: 617-634.

21. Rapoport DM, Garay SM, Epstein H, Goldring RM. Hypercapnia in the obstructive sleep apnea syndrome. A reevaluation of the "Pickwickian syndrome". Chest 1986; 89: 627-635.

22. Sullivan CE, Berthon-Jones M, Issa FG. Remission of severe obesity-hypoventilation syndrome after short-term treatment duing sleep with nasal continuous positive airway pressure. Am Rev Respir Dis 1983: 128: 177-181.

23. Rapoport DM, Sorkin B, Garay SM, Goldring RM. Reversal of the "Pickwickian syndrome" by long-term use of nocturnal nasal-airway pressure. $N$ Engl J Med 1982; 307: 931-933.

24. Pankow W, Fett I, Schaudt D, Kohl F-V. Exzessive Tagesmüdigkeit mit psychotischer Symptomatik bei Pickwick-Syndrom. Med Klin 1995; 90: 490-494.

25. Pelosi P, Croci M, Ravagnan I, Vicardi P, Gattinoni L. Total respiratory system, lung, and chest wall mechanics in sedated-paralyzed postoperative morbidly obese subjects. Chest 1996; 109: 144-151.

26. Fox GS, Whalley DG, Bevan OR. Anesthesia for the morbidly obese: experience with 110 patients. Br J Anaesth 1981; 53: 811-816.

27. Shenkman Z, Shir Y, Brodsky JB. Perioperative management of the obese patient. Br J Anaesth 1993; 70: 349-359.

28. Vaughan RW. Anesthetic considerations in jejunoileal small bowel bypass for morbid obesity. Anesth Analg 1974; 53: 421-429. 